The International Journal of Indian Psychology: Volume: 01 | Issue: 04 No. 2 | ISSN 2348-5396

\title{
Health and Adjustment of High School Students
}

\author{
Dr. Thiyam Kiran Singh*, Sanjeev Tripathi**, Prof. J. Mahato***
}

\begin{abstract}
In this study random sampling technique was used in which total samples of 186 were collected out of which 72 were boys and 114 were girls with the age range of 13 to 18 years. All these participants were administered P.G.I. Health Questionnaire developed by Verma, Wig and Prasad (1978) and Bell Adjustment Inventory developed by Mohsin and Shamshad (1968) to find out healthy students and unhealthy students. The purpose of the study is to compare boys and girls on Bell Adjustment Inventory to find out any significant difference in home adjustment, health adjustment, social adjustment, emotional adjustment and overall adjustment. Another purpose is to compare healthy group and unhealthy group on Bell Adjustment Inventory to find out any significant difference in home adjustment, health adjustment, social adjustment, emotional adjustment and overall adjustment. The result found no significant between boys and girls in the domains of Bell Adjustment Inventory: home adjustment, health adjustment, social adjustment, emotional adjustment and overall adjustment. Where as the result found significant in comparison between healthy students and unhealthy students in all the domains of Bell Adjustment Inventory: home adjustment, health adjustment, social adjustment, emotional adjustment and overall adjustment which signifies that healthy students were adjusted well in all the domains of Bell Adjustment Inventory mentioned above.
\end{abstract}

Key words: - General Health, Adjustment, High school, Students.

School mental health and adjustment problems are the most fascinating study area of these days. Students of higher classes are under constant pressure of competition with peers, about future of career opportunities, parents and teachers expectation etc. These issues can lead to-

\footnotetext{
*Assistant Professor, Dept. of Psychology, AIBAS, Amity University, Rajasthan.

**Consultant Clinical Psychologist, Greater kailash Hospital, Indore.

***Dept. Of Clinical Psychology, Post Graduate Institute of Behavioural and Allied Sciences, Raipur (C.G).
} 
- adjustment problems in teenager and adolescent students. Many mental disorders have their beginnings in childhood or adolescence. The school is the major socialization institution for any child. It is the child's first contract with the world outside the house. For nearly 12 years a child spends 5 to 7 hours a day in the school. School is one the most important foundation pillars on which the child's personality develops. Children learn proficiencies in various abilities like, learning process and home work, social communications, handling emotion, and the management of day to day interactions at home and school. In reality, the growing child is dependent on the immediate environment i.e. the house and the school to meet his growth needs. The concern therefore extends to how the school facilities can be enhanced and improved to meet the growth needs of the children. Several studies have been reported in the area of social, educational, health and emotional adjustment of school students of both sexes. Some studies try to relate adjustment with variables like intelligence, achievement, age, sex, socio-economic status, needs, anxiety, and security. Student's reaction to frustration has also been studied. A few studies focused on the nature, causes and extent of indiscipline among students. The relation between indiscipline and variables like achievement, participation in co curricular activities etc. were also examined. A review of the studies carried out in the field of adjustment as reported in the three surveys of educational research edited by Buch (1991) reveals that no systematic attempt has yet been made to develop a tool for the assessment of adjustment problems of school students. Child and adolescent mental health and adjustment have been largely a neglected area in India. Researches in the area of child and adolescent mental health of rural and urban areas is negligible and epidemiological information gathered in this area cannot be generalized because of methodological limitations like small and non-representative samples and the lack of standardized screening tools. Prevalence studies reveal the prevalence of clinically significant child and adolescent psychopathology ranging from $1.56 \%$ to $35.5 \%$ in school going children (Bhasin etal, 2010). Surveys of individual psychiatric disorders and of incidence and period prevalence are yet to be conducted in this population of children. Looking into this perspective, current research work has been carried out in the area of high school students to identify the problematic areas for adjustment so that an adequate management and preventive measures could be formulate. 
The International Journal of Indian Psychology: Volume: 01 | Issue: 04 No. 2 | ISSN 2348-5396

\section{METHODOLOGY}

\section{Aim:}

The aim of this study is to assess the health and adjustment among school going children and adolescents.

\section{Hypotheses:}

1. There will be mental health problems in high school going students.

2. There will be adjustment problems in high school going students

3. There will be significant relationship in adjustment and mental health of high school going students.

\section{Research Design:}

This research was adopted by using completely randomized designs as it studied the effects of one primary factor i.e. health on adjustment without the need to take other nuisance variables into account.

\section{Sample:}

Sample of 186 (72 Boys and 114 Girls) students in the age range 13 to 18 years from four schools of Raipur city were collected randomly for the study.

\section{Inclusion Criteria:}

- Students in the age range of 13 to 18 years were included.

- Students of class $9^{\text {th }}$ to $12^{\text {th }}$ were included for the study.

- 94 Healthy and 92 Unhealthy high school students.

- Those who were able to comprehend the instructions and cooperative.

\section{Exclusion Criteria:}

- Students above or below the age range of 13 to 18 years were excluded.

- Students other than class IX $^{\text {th }}$ to XII ${ }^{\text {th }}$ were excluded.

- Who were not able to comprehend the instructions and uncooperative. 
The International Journal of Indian Psychology: Volume: 01 | Issue: 04 No. 2 | ISSN 2348-5396

\section{Tools Used:}

\section{PGI Health Questionnaire:}

This questionnaire has been developed by Verma N.N. Wig and D.Prasad (1978). The test consists of 38 items having two dimensions namely, physical and psychological. The number of ticks on section 'A' and 'B' indicate the respective scores, which can be then added up to give a total score also. The test retest reliability is 0.88 split-half reliability is 0.86 and inter co-relation is 0.81 .

\section{Bell Adjustment Inventory (Mohsin \& Shamshad, 1968):}

Mohsin \& Samshad's Indian adaptation of Bell adjustment inventory (Hindi form) was used to assess the adjustment of sample group. It consists of 135 items, retained as a result of item analysis, out of 140 items. The inventory measures adjustment in four different areas - home, health, social, and emotional. Its reliability ranges from 0.70 to 0.92 and validity is also very high.

\section{Procedure:}

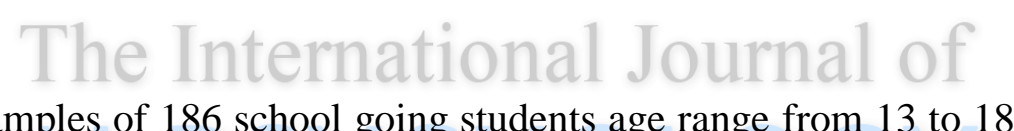

In this study the total samples of 186 school going students age range from 13 to 18 years fulfilling inclusion and exclusion criteria from class IX to XII were collected. They were administered PGI Health questionnaire to check healthy and unhealthy students and Bell Adjustment Inventory to check their adjustment regarding home, health, social, emotional and over all adjustment. The data were collected from four different schools in Raipur city. The study was conducted in reputed institution namely Post Graduate Institute of Behavioural and Medical Sciences (PGIBMS), Raipur.

\section{Statistical Analysis:}

Statistical Analysis was done using the statistical software namely Statistical Package of Social Science (SPSS-16.0) 
The International Journal of Indian Psychology: Volume: 01 | Issue: 04 No. 2 | ISSN 2348-5396

\section{RESULTS:}

Tables:

Table 1 Shows, the Mean age and S.D. of High School Students.

\begin{tabular}{|l|c|c|}
\hline Variables & Mean & SD \\
\hline Age & 14.87 & 1.39 \\
\hline
\end{tabular}

Table show the mean age and standard deviation of high school students and found 14.8 years of mean with SD of 1.39 .

Table 2 Shows, comparison of high school Boys and Girls students on Bell Adjustment Inventory.

\begin{tabular}{|c|c|c|c|c|c|c|}
\hline $\begin{array}{l}\text { Bell } \\
\text { Adjustment } \\
\text { Inventory }\end{array}$ & $\begin{array}{l}\text { Student's } \\
\text { Group }\end{array}$ & $\mathrm{N}$ & $\begin{array}{l}\text { Mean of } \\
\text { maladjustment }\end{array}$ & SD & SE & $\mathrm{t}-$ Value \\
\hline \multirow{2}{*}{ Home } & Boys & 72 & 2.361 & 1.281 & 0.151 & \multirow[t]{2}{*}{0.984} \\
\hline & Girls & 114 & 2.175 & 1.235 & 0.115 & \\
\hline \multirow[t]{2}{*}{ Health } & Boys & 72 & 2.444 & 1.220 & 0.143 & \multirow[t]{2}{*}{1.159} \\
\hline & Girls & 114 & 2.236 & 1.169 & 0.109 & \\
\hline \multirow[t]{2}{*}{ Social } & Boys & 72 & 2.361 & 1.011 & 0.119 & \multirow[t]{2}{*}{0.101} \\
\hline & Girls & 114 & $2.37712 t e 11$ & 1.084)12a & 0.101 ulp & \\
\hline \multirow[t]{2}{*}{ Emotional } & Boys & 72 & 2.555 & 1.099 & 0.129 & \multirow[t]{2}{*}{0.220} \\
\hline & Girls & 114 & 2.517 & 1.176 & 0.110 & \\
\hline Overall & Boys & 72 & 2.694 & 1.182 & 0.139 & \multirow[t]{2}{*}{1.611} \\
\hline Adjustment & Girls & 114 & 2.403 & 1.209 & 0.113 & \\
\hline
\end{tabular}

*Significant at 0.05 level (2-tailed) **Significant at 0.01 level (2-tailed)

Table shows comparison of high school Boys and Girls students on Bell Adjustment Inventory and the result found no significant difference in all the domains- Home adjustment, Health adjustment, Social adjustment, Emotional adjustment and Overall adjustment. 
The International Journal of Indian Psychology: Volume: 01 | Issue: 04 No. 2 | ISSN 2348-5396

Table 3 Shows, details of High School Students on Bell Adjustment Inventory and PGI Health Questionnaire.

\begin{tabular}{|l|l|l|l|l|l|l|}
\hline $\begin{array}{l}\text { Bell } \\
\text { Adjustment } \\
\text { Inventory }\end{array}$ & $\begin{array}{l}\text { PGI Health } \\
\text { Questionnaire }\end{array}$ & $\mathrm{N}$ & $\begin{array}{l}\text { Mean of } \\
\text { maladjustment }\end{array}$ & SD & SE & t- Value \\
\hline \multirow{2}{*}{ Home } & Healthy & 94 & 1.776 & 1.038 & 0.107 & \multirow{2}{*}{$5.584^{*}$} \\
\cline { 2 - 7 } & Unhealthy & 92 & 2.729 & 1.276 & 0.133 & \\
\hline \multirow{2}{*}{ Health } & Healthy & 94 & 1.744 & 1.004 & 0.103 & \multirow{2}{*}{$7.570^{* *}$} \\
\cline { 2 - 6 } & Unhealthy & 92 & 2.902 & 1.079 & 0.112 & \\
\hline \multirow{2}{*}{ Social } & Healthy & 94 & 2.085 & 0.980 & 0.101 & \multirow{2}{*}{$3.879^{*}$} \\
\cline { 2 - 6 } & Unhealthy & 92 & 2.663 & 1.051 & 0.109 & \\
\hline \multirow{2}{*}{ Emotional } & Healthy & 94 & 1.968 & 1.062 & 0.109 & \multirow{2}{*}{$7.824^{* *}$} \\
\cline { 2 - 6 } & Unhealthy & 92 & 3.108 & 0.919 & 0.095 & \\
\hline \multirow{2}{*}{$\begin{array}{l}\text { Overall } \\
\text { Adjustment }\end{array}$} & Healthy & 94 & 1.957 & 1.046 & 0.107 & \multirow{2}{*}{$7.224^{* *}$} \\
\cline { 2 - 6 } & Unhealthy & 92 & 3.087 & 1.085 & 0.113 & \\
\hline
\end{tabular}

*Significant at 0.05 level (2-tailed) **Significant at 0.01 level (2-tailed)

Table shows comparison of healthy and unhealthy High School Students on Bell Adjustment and the result found significantly different under the domains of Home adjustment $(\mathrm{t}=5.584, \mathrm{P}<$ $0.05)$, Health adjustment $(t=7.570, P<0.01)$, Social adjustment $(t=3.879, P<0.05)$, Emotional adjustment $(\mathrm{t}=7.824, \mathrm{P}<0.01)$ and Overall adjustment $(\mathrm{t}=7.224, \mathrm{P}<0.01)$ of Bell adjustment inventory which signifies that healthy students are well adjusted in the domains of - Home, Health, Social, Emotional and Overall adjustment than unhealthy students.

Table 4 Shows, co-relationship between Bell Adjustment Inventory and PGI Health Questionnaire.

\begin{tabular}{|l|l|l|l|l|l|l|}
\hline Variables & Home & Health & Social & Emotional & $\begin{array}{l}\text { Overall } \\
\text { Adjustment }\end{array}$ & $\begin{array}{l}\text { PGI Health } \\
\text { Questionnaire }\end{array}$ \\
\hline Home & 1 & $0.697^{* *}$ & $0.290^{* *}$ & $0.722^{* *}$ & $0.792^{* *}$ & $0.381^{* *}$ \\
\hline Health & $0.697^{* *}$ & 1 & $0.354^{* *}$ & $0.645^{* *}$ & $0.703^{* *}$ & $0.487^{* *}$ \\
\hline Social & $0.290^{* *}$ & $0.354^{* *}$ & 1 & $0.508^{* *}$ & $0.572^{* *}$ & $0.275^{* *}$ \\
\hline Emotional & $0.722^{* *}$ & $0.645^{* *}$ & $0.508^{* *}$ & 1 & $0.847^{* *}$ & $0.500^{* *}$ \\
\hline $\begin{array}{l}\text { Overall } \\
\text { Adjustment }\end{array}$ & $0.792^{* *}$ & $0.703^{* *}$ & $0.572^{* *}$ & $0.847^{* *}$ & 1 & $0.470^{* *}$ \\
\hline $\begin{array}{l}\text { PGI Health } \\
\text { Questionnaire }\end{array}$ & $0.381^{* *}$ & $0.487^{* *}$ & $0.275^{* *}$ & $0.500^{* *}$ & $0.470^{* *}$ & 1 \\
\hline
\end{tabular}

*Significant at 0.05 level (2-tailed) **Significant at 0.01 level (2-tailed) 
The International Journal of Indian Psychology: Volume: 01 | Issue: 04 No. 2 | ISSN 2348-5396

Table shows correlation between Bell Adjustment Inventory and PGI Health Questionnaire and the result found significantly positive correlation in all the domains of Bell adjustment inventory and PGI Health questionnaire which signifies that with the increase in General health the overall adjustments in terms of home, health, social and emotional also increased.

\section{DISCUSSION:}

The result found no significant difference between boys and girls in all the domains and overall adjustment. Similarly, Gupta and Gupta (2011) conducted a study on 100 students who were selected from various schools of Meerut. In which two groups were formed according to their gender. Mean, S.D. \& Critical Ratio were calculated. They found boys and girls have same order of adjustment. It means the opinion of teachers of co-educational institution that girls adjust better than boys is wrong. Adhiambo, et al. (2011) did a study on the relationship among school adjustment, gender and academic achievement amongst secondary school students in Kisumu district Keny and the result found that there were no significant differences between girls and boys in school adjustment.

The result shows significant difference while comparing two group i.e. healthy group and unhealthy group under the domains of home adjustment, health adjustment, social adjustment, emotional adjustment and overall adjustment of Bell adjustment inventory. The findings indicates that students who have better mental health also have better adjustment in the dimensions of - Home, Health, Social and Emotional. This may be because healthy students might be getting benefit from medium of instructions of schools, management of the schools, possess good mental health and also may have good environment. Supportively, Raju and Rahamtulla (2007) found out that adjustment of school children is primarily dependent on the school variables like the class in which they are studying, the medium of instruction present in the school and the type of management of the school. Parental education and occupation of the school children also significantly influenced adjustment. In the study of Sinha (2010) those prisoners who obtained poor adjustment in social and emotional areas has significant association between mental health problems. Khokhar (2007) found deprived adolescents from enriched environmental stimulation have lower self-adjustment. Poor environmental surrounding such as lack of good houses, neat and clean water sunlight and fresh air deteriorate the self-adjustment of adolescents. In the study of Clark (2005) the result found social support is one of most important 
The International Journal of Indian Psychology: Volume: 01 | Issue: 04 No. 2 | ISSN 2348-5396

factors in predicting the physical health and well-being of everyone, ranging from childhood through older adults. The absence of social support shows some disadvantage among the impacted individuals. In most cases, it can predict the deterioration of physical and mental health among the victims.

The result found significantly positive co-relation in all domains of Bell adjustment inventory and PGI Health questionnaire which signifies that with the increase in general health the overall adjustments in terms of home, health, social and emotion increased and with the decrease of general health the overall adjustment were also decrease. Likewise, Roy (2012) found in his study that mentally retarded subjects had greater adjustment problems than the normal control group. $\underline{\text { Hans }}$ et al. (2000) found young people with schizophrenia showed poor peer engagement, particularly heterosexual engagement and social problems characterized by immaturity and unpopularity with peers. Young people whose parents had other disorders showed different patterns of social maladjustment characterized by difficult, conflictual relationships with peers and family. Lewis and Darby (2004) found maternal depressed mood and the quality of the parent-child relationship significantly influenced adolescent adjustment during the acute phase of the mother's breast cancer.

\section{SUMMARY AND CONCLUSION}

The study was conducted to assess the health and adjustment among school going students. In this study a sample of 186 students were taken from four different schools of Raipur as per inclusion and exclusion criteria using random sampling method. From this study it can be concluded that there is no significant difference between boys and girls in the domains of home adjustment, health adjustment, social adjustment, emotional adjustment and overall adjustment. Whereas the result significant difference in comparison between healthy students and unhealthy students in the domains of home adjustment, health adjustment, social adjustment, emotional adjustment and overall adjustment of Bell Adjustment Inventory which signifies that healthy students were adjusted well in the domains of home, health, social, emotional and overall adjustment. 
The International Journal of Indian Psychology: Volume: 01 | Issue: 04 No. 2 | ISSN 2348-5396

\section{REFERENCES:}

1. Adhiambo,W.M., Odwar, A.J., \& Mildred, A.A. (2011).The Relationship among School Adjustment, Gender and Academic Achievement amongst Secondary School Students in Kisumu District Kenya. Journal of Emerging Trends in Educational Research and Policy Studies (JETERAPS), 2 (6), 493-497.

2. Bhasin, A., Khan, W., \& Singh, T.B. (2010). Prevalence of Mental Disorders among School children. An unpublished PhD thesis submitted to Jamia Milia Islamia University, INHAS. Retrieved from: http:// www.jmi.ac.in/upload/employeeresume/wkhan.pdf on 19/5/2014.

3. Buch, M.B. (Ed) (1991). Survey of research in education, New Delhi: NCERT.

4. Clark, C.M. (2005). Relations between social support and physical health. Retrieved from: http://www.personalityresearch.org/papers/clark.html on 19/5/2014.

5. Devi, N. (2011). A study of adjustment of students in relation to personality and achievement motivation. Bhartiya international Journal of education and research, l(1), Retrieved from: htt://www.gangainstituteofeducation.com/.../ASTUDYOFADJUSTMENTOFSTUDE...o n $18 / 5 / 2014$.

6. Gupta, M., \& Gupta, R. (2011). Adjustment and Scholastic Achievement of Boys \& Girls. VSRD International Journal of Business Management Research, 1 (1), 2011, 2933.

7. Hans, S.L., Auerbach, J.G., Asarnow, J.R., Styr, B., \& Marcus J. (2000). Social Adjustment of Adolescents at Risk for Schizophrenia: The Jerusalem Infant Development Study._Journal of the American Academy of Child \& Adolescent Psychiatry, 39 (11), 1406-1414.

8. Khokhar, C.P. (2007). Poor Physical environment and adjustment of adolescents. Europe's Journal of Psychology, 3(3). Retrieved from: http://ejop.psychopen.eu/article/view/407/306 on 18/5/2014

9. Lewis, F.M., \& Darby, E.L. (2004). Adolescent Adjustment and Maternal Breast Cancer. Journal of Psychosocial Oncology, 21(4), 81-104. Retrieved from: 
The International Journal of Indian Psychology: Volume: 01 | Issue: 04 No. 2 | ISSN 2348-5396

http://www.tandfonline.com/doi/abs/10.1300/J077v21n04_05\#.U3jxtye6bXQ

on $18 / 5 / 2014$.

10. Mohsin, S. (1968). Manual for Mohsin-Samshad Hindi Adaptation of Bell Adjustment Inventry. Retrieved from: http://www.industrialpsychiatry.org/article.asp?issn=09726748; year=2010; volume=19; issue $=2 ;$ spage $=101$; epage $=104 ;$ aulast $=$ Sinha on 17/5/2014 .

11. Raju, M.V.R., \& Rahamtulla, T.K. (2007). Adjustment Problems among School Students. Journal of the Indian Academy of Applied Psychology, 33 (1), 73-79.

12. Roy, B. (2012). Adjustment problems of educable mentally retarded. International Journal of Scientific and Research Publications, 2 (6), 1-5.

13. Sinha, S. (2010). Adjustment and mental health problem in prisoners. Industrial Psychiatry Journal,_19(2), 101-104.

14. Verma, S.K., Wig, N.N., Parshad, D. (1978). Manual for PGL Health Questionnaire No.1, Agra: National Psychological Corporation. 